\title{
An open-label feasibility study of nintedanib combined with docetaxel in Japanese patients with locally advanced or metastatic lung adenocarcinoma after failure of first-line chemotherapy
}

\author{
Noboru Yamamoto ${ }^{1} \cdot$ Hirotsugu Kenmotsu ${ }^{2} \cdot$ Koichi Goto $^{3} \cdot$ Koji Takeda $^{4} \cdot$ Terufumi Kato $^{5} \cdot$ Masayuki Takeda ${ }^{6}$. \\ Hidehito Horinouchi ${ }^{1} \cdot$ Isao Saito $^{7} \cdot$ Akiko Sarashina $^{8} \cdot$ Tetsuya Tanaka $^{9} \cdot$ Nassim Morsli $^{10} \cdot$ Kazuhiko Nakagawa $^{6}$
}

Received: 13 June 2018 / Accepted: 12 July 2018 / Published online: 3 August 2018

(c) The Author(s) 2018

\begin{abstract}
Purpose This open-label feasibility study assessed the tolerability of nintedanib $200 \mathrm{mg}$ in combination with docetaxel $75 \mathrm{mg} / \mathrm{m}^{2}$ as a starting dose in Japanese patients with a body surface area (BSA) $<1.5 \mathrm{~m}^{2}$ and locally advanced or metastatic lung adenocarcinoma.

Methods Eligible patients received docetaxel $75 \mathrm{mg} / \mathrm{m}^{2}$ every 21 days and nintedanib administered at $200 \mathrm{mg}$ twice daily (bid), starting on day 2 of each cycle. Treatment was continued until disease progression or undue toxicity. The primary endpoint was the number of patients experiencing dose-limiting toxicities (DLTs) in cycle 1 (days 1-21).

Results Of 10 treated patients, 2 patients (20\%) experienced DLTs during cycle 1 . These DLTs were grade 3 liver enzyme elevations [alanine aminotransferase ( 2 patients) and aspartate aminotransferase ( 2 patients)], and grade 2 hyperbilirubinemia (1 patient). Nine patients met the predefined criteria for nintedanib $200 \mathrm{mg}$ bid plus docetaxel $75 \mathrm{mg} / \mathrm{m}^{2}$ to be considered a tolerable starting dose. All patients experienced $\geq 1$ adverse event (AE) during the treatment period (all drug-related), but no patients experienced AEs that led to discontinuation of nintedanib. Of the five serious AEs reported during treatment, none were drug-related. There was no apparent effect of nintedanib on the pharmacokinetics of docetaxel. The objective response and disease control rates were 40 and $70 \%$, respectively.

Conclusion Nintedanib $200 \mathrm{mg}$ bid plus docetaxel $75 \mathrm{mg} / \mathrm{m}^{2}$ is a tolerable starting dose in Japanese patients with a $\mathrm{BSA}<1.5 \mathrm{~m}^{2}$ with locally advanced or metastatic lung adenocarcinoma.

ClinicalTrials.gov number NCT02300298.
\end{abstract}

Keywords Adenocarcinoma $\cdot$ Docetaxel $\cdot$ Japanese $\cdot$ Nintedanib $\cdot$ Non-small cell lung cancer

\section{Introduction}

Prior to 2016, effective second-line treatment options in nonsmall cell lung cancer (NSCLC), particularly in patients with adenocarcinoma who are not eligible for epidermal growth factor receptor (EGFR)- or anaplastic lymphoma kinase (ALK)-targeted therapy, were limited [1, 2]. Despite recent Food and Drug Administration approval of the immunotherapies nivolumab, pembrolizumab, and atezolizumab in this setting, there remains a clinical need for treatment options with better efficacy than docetaxel in patients with

Noboru Yamamoto

nbryamam@ncc.go.jp

Extended author information available on the last page of the article aggressive disease whose tumors have low or absent programmed death-ligand 1 expression [3-6].

Nintedanib is an oral, triple angiokinase inhibitor that targets vascular endothelial growth factor (VEGF) receptors $1-3$, fibroblast growth factor receptors $1-3$, and plateletderived growth factor receptors $\alpha / \beta$. In addition, nintedanib inhibits receptor kinases of RET, Flt3, and the Src family [7].

Nintedanib, in combination with docetaxel, is approved in the European Union and other countries for the treatment of patients with locally advanced, metastatic, or locally recurrent NSCLC of adenocarcinoma histology after first-line chemotherapy $[8,9]$. The efficacy and safety of nintedanib combined with docetaxel was confirmed in the phase III LUME-Lung 1 trial, in which the median overall survival of patients with adenocarcinoma who 
received docetaxel $75 \mathrm{mg} / \mathrm{m}^{2}$ plus nintedanib $200 \mathrm{mg}$ twice daily (bid) was significantly longer than that in patients who received docetaxel plus placebo [10]. This treatment is, therefore, considered to be an effective second-line option for patients with advanced lung adenocarcinoma after failure of platinum-based therapy [10].

Phase I trials of nintedanib monotherapy have reported a difference between Japanese and European patients in the maximum tolerated dose (MTD) of nintedanib [11, 12]. Although liver enzyme elevations were among the dose-limiting toxicities (DLTs) of nintedanib in both Japanese and European patients, they occurred at a greater frequency in Japanese patients who were treated with the same doses, a finding that led to a difference in the MTD of nintedanib between European (250 mg bid) and Japanese $(200 \mathrm{mg}$ bid) patients $[11,12]$. In a previous pharmacokinetic (PK) study, the authors noted that there was no difference in the reported $\mathrm{PK}$ profile of nintedanib between Japanese and European patients [11, 12], but that patient body size may affect the frequency of adverse events (AEs) $[11,12]$.

A phase I, open-label trial in Japanese patients with advanced NSCLC who received docetaxel 60 or $75 \mathrm{mg} /$ $\mathrm{m}^{2}$ (on day 1) plus nintedanib 100,150 , or $200 \mathrm{mg}$ bid (on days 2-21) reported that the MTD of nintedanib in combination with docetaxel $75 \mathrm{mg} / \mathrm{m}^{2}$ was $200 \mathrm{mg}$ bid in patients with a body surface area (BSA) $\geq 1.5 \mathrm{~m}^{2}$, but $150 \mathrm{mg}$ bid in patients with a BSA $<1.5 \mathrm{~m}^{2}$ [13]. This was because all patients with a BSA $<1.5 \mathrm{~m}^{2}$ who were treated with nintedanib $200 \mathrm{mg}$ bid plus docetaxel $60 \mathrm{mg} /$ $\mathrm{m}^{2}$ experienced DLTs during cycle 1 , whereas only 1 of 6 patients with a BSA $<1.5 \mathrm{~m}^{2}$ who were treated with nintedanib $150 \mathrm{mg}$ bid plus docetaxel $75 \mathrm{mg} / \mathrm{m}^{2}$ experienced DLTs during cycle 1 . Given this, the lower nintedanib dose level (150 mg bid) was identified as the MTD in these patients. However, the majority of DLTs were dose-dependent liver enzyme elevations [alanine aminotransferase (ALT), gamma-glutamyltransferase (GGT), and aspartate aminotransferase (AST)] that were reversible with dose reduction and discontinuation [13]. Therefore, nintedanib $200 \mathrm{mg}$ bid plus docetaxel $75 \mathrm{mg} / \mathrm{m}^{2}$, which had not been evaluated previously, was considered to be a potential starting dose in patients with a BSA $<1.5 \mathrm{~m}^{2}$ that warranted further investigation.

Consequently, we carried out an open-label, feasibility study to assess the tolerability of nintedanib $200 \mathrm{mg}$ bid in combination with docetaxel $75 \mathrm{mg} / \mathrm{m}^{2}$ as a starting dose in Japanese patients with a BSA $<1.5 \mathrm{~m}^{2}$. Patients had locally advanced or metastatic lung adenocarcinoma that had progressed after first-line, platinum-based chemotherapy. The primary endpoint of the study was the number of patients experiencing a DLT during cycle 1 .

\section{Materials and methods}

\section{Study design and patients}

This study was an open-label feasibility trial (phase Ib) in 10 Japanese patients. The study was conducted at 6 centers in Japan.

Eligible patients were $\geq 20$ years old, with a BSA $<1.5 \mathrm{~m}^{2}$ at screening and histologically/cytologically confirmed locally advanced or metastatic lung adenocarcinoma after the failure of first-line platinumbased chemotherapy. Patients had a life expectancy of $\geq 3$ months and an Eastern Cooperative Oncology Group performance status of 0 or 1 at screening. Patients who had received more than 1 prior line of chemotherapy for advanced or metastatic NSCLC were excluded from the study, as were patients who had received previous therapy with other VEGF or VEGF receptor inhibitors (other than bevacizumab) for the treatment of NSCLC at any time. Patients who had received other investigational drugs, chemotherapy, hormone therapy, immunotherapy, or monoclonal antibodies within 4 weeks of the start of the study, and those who had received molecular targeted therapy (including EGFR tyrosine kinase inhibitors and ALK inhibitors) within 2 weeks of the start of the study were also excluded.

All patients provided written informed consent. The study complied with the Declaration of Helsinki and was carried out in accordance with good clinical practice or regulatory guidelines and relevant local legislation. The protocol was approved by the independent ethics committee or institutional review boards at each center. An independent safety review committee continually monitored the safety of all patients taking part in the study.

\section{Procedures}

All patients received docetaxel $75 \mathrm{mg} / \mathrm{m}^{2}$ by intravenous infusion over $1 \mathrm{~h}$ every 21 days with appropriate previous and concomitant medication, and nintedanib capsules were administered as an oral daily dose of $400 \mathrm{mg}$ (200 mg in the morning and $200 \mathrm{mg}$ in the evening after meals) starting on day 2 of each cycle.

There was no prespecified maximum number of treatment cycles; treatment was continued as long as patients did not meet any of the treatment discontinuation criteria, such as disease progression or undue toxicity. In the case of related AEs, 2 dose reduction steps were permitted for both docetaxel and nintedanib. Docetaxel could be reduced from 75 to $60 \mathrm{mg} / \mathrm{m}^{2}$ for the first dose reduction and from 60 to $50 \mathrm{mg} / \mathrm{m}^{2}$ for the second dose reduction. Nintedanib 
could be reduced from 200 to $150 \mathrm{mg}$ bid for the first dose reduction and from 150 to $100 \mathrm{mg}$ bid for the second dose reduction. No dose increases were allowed after a dose reduction for either nintedanib or docetaxel.

Patients who had to discontinue docetaxel for reasons other than disease progression were allowed to continue treatment with nintedanib monotherapy. Patients were monitored at regular intervals for evaluation of safety, assessment of compliance, recording of AEs, and additional examinations. Tumor response was assessed using Response Evaluation Criteria in Solid Tumors version 1.1, at baseline and on day 1 of every odd cycle after cycle 3 until disease progression. AEs, classified according to the Common Terminology Criteria for Adverse Events (CTCAE) version 3.0, were recorded during the study period. A serious AE (SAE) was defined as any AE that resulted in death, was immediately life-threatening, resulted in persistent or significant disability/incapacity, needed admission to hospital or prolonged admission to hospital, or was a congenital anomaly or birth defect. Other events were deemed serious if, on the basis of appropriate medical judgment, the event might jeopardize the patient and need medical or surgical intervention to prevent one of the other outcomes listed in the above definition. Patients were monitored for AEs throughout the study according to the visit schedule defined in the protocol.

\section{Evaluation of appropriate starting dose}

The appropriateness of nintedanib $200 \mathrm{mg}$ bid plus docetaxel $75 \mathrm{mg} / \mathrm{m}^{2}$ as a starting dose was evaluated by the safety review committee comprising 3 physicians with considerable experience in the management of NSCLC in the clinical trial setting. This committee reviewed data from study participants according to the following predefined criteria: (1) a patient who completed cycle 1 without any DLTs; (2) a patient who experienced a DLT of CTCAE grade $\geq 3$ AST and/or ALT increase, or CTCAE grade 2 AST and/or ALT increase in conjunction with CTCAE grade $\geq 1$ total bilirubin in cycle 1 but could be retreated with the combination of nintedanib $150 \mathrm{mg}$ plus docetaxel $75 \mathrm{mg} / \mathrm{m}^{2}$ and completed cycle 2 without any further DLT.

If a patient experienced DLTs other than CTCAE grade $\geq 3$ AST and/or ALT increase, the starting dose was not considered to be appropriate, even if nintedanib could be administered at a reduced dose. If $\geq 4$ patients experienced DLTs other than CTCAE grade $\geq 3$ AST and/or ALT increase in cycle 1 during the enrollment period, the investigators were to halt patient recruitment and discuss next steps with the safety review committee.

\section{Outcomes}

The primary endpoint was the number of patients experiencing DLTs in cycle 1 (days 1-21), according to the CTCAE version 3.0. DLTs are defined in Table 1.

Secondary endpoints included PK parameters for nintedanib and docetaxel: maximum measured concentration of the analyte in plasma $\left(C_{\max }\right)$, area under the concentration-time curve of the analyte in plasma over the time interval from 0 to time of the last quantifiable plasma concentration $\left(\mathrm{AUC}_{0-\mathrm{tz}}\right)$, and area under the concentration-time curve of the analyte in plasma over the time interval from 0 extrapolated to infinity $\left(\mathrm{AUC}_{0-\infty}\right)$.

Safety endpoints included the number of patients with AEs according to CTCAE (version 3.0) for overall AEs, SAEs, drug-related AEs, AEs leading to dose reduction or treatment discontinuation, AEs of special interest, and changes in laboratory parameters. The objective response rate (percentage of patients whose best overall response was complete response or partial response) and disease control rate (percentage of patients whose best overall response was complete response, partial response or stable disease) were evaluated as further endpoints.

\section{Statistical analysis}

Descriptive statistics only were used in this study; no statistical model was adopted. The analysis sets were defined

Table 1 Definitions of dose-limiting toxicities

Criteria

CTCAE grade $\geq 3$ non-hematologic toxicity (except transient electrolyte abnormality and isolated increase of GGT)

Gastrointestinal toxicity (e.g., nausea, vomiting, diarrhea, abdominal pain) despite adequate supportive care

CTCAE grade 4 hematological toxicity

Decreased neutrophil count (not associated with fever $\geq 38.5^{\circ} \mathrm{C}$ ) for $>7$ days, despite adequate supportive treatment (e.g., G-CSF)

Decreased WBC count for $>7$ days, despite adequate supportive treatment (e.g., G-CSF)

CTCAE grade 4 febrile neutropenia associated with fever $\geq 38.5^{\circ} \mathrm{C}$

CTCAE grade $\geq 2$ ALT and/or increased AST in conjunction with CTCAE grade $\geq 2$ increase of total bilirubin

Inability to resume nintedanib dosing within 14 days after stopping because of toxicity

ALT alanine aminotransferase, AST aspartate aminotransferase, CTCAE Common Terminology Criteria for Adverse Events, GGT gamma-glutamyltransferase, $G$ - $C S F$ granulocyte-colony stimulating factor, $W B C$ white blood cell 
for the analysis of safety, efficacy, and PK. The treated set included all patients who received study medication and were documented to have taken $\geq 1$ dose of study treatment (docetaxel or nintedanib); this patient set was used for the analysis of safety and efficacy except for the primary endpoint. The feasibility set included all patients who were included in the treated set, except any replaced patients; this patient set was used for the analysis of the primary endpoint. The PK set included all patients in the treated set who had $\geq 1$ available valid drug plasma concentration; this patient set was used for the analysis of PK.

The incidence of DLTs graded according to CTCAE version 3.0 was evaluated; the frequency, severity, and causal relationship of AEs were tabulated by system organ class and preferred term after coding according to version 18.1 of the Medical Dictionary for Regulatory Activities. AEs and laboratory parameters were graded according to the CTCAE version 3.0. PK parameters were calculated by standard non-compartmental methods. Best overall response was tabulated in frequency $(\%)$.

\section{Results}

\section{Patient demographics}

A total of 10 patients ( 2 male and 8 female) with locally advanced or metastatic lung adenocarcinoma were enrolled between January 2015 and September 2015. As of the data cut-off (April 2016), 2 patients were still receiving treatment with nintedanib monotherapy (Fig. 1). The reason for discontinuation of nintedanib was progressive disease in all 8 patients. The most common reason for discontinuation of docetaxel was progressive disease [6 patients $(60 \%)$ ], followed by other AEs [4 patients (40\%)].

The demographics and clinical characteristics of the patients are listed in Table 2. The median age of patients was 69 years and the median BSA was $1.45 \mathrm{~m}^{2}$. All 10 patients had previously been treated with platinum-based chemotherapy: 7 patients with cisplatin and 3 patients with carboplatin. The majority of patients were on doublet combination treatment that included pemetrexed (7 patients); other patients were on doublet combination treatment that included vinorelbine ( 2 patients), or quartet combination treatment, including paclitaxel, bevacizumab, and GDC0941 (1 patient).

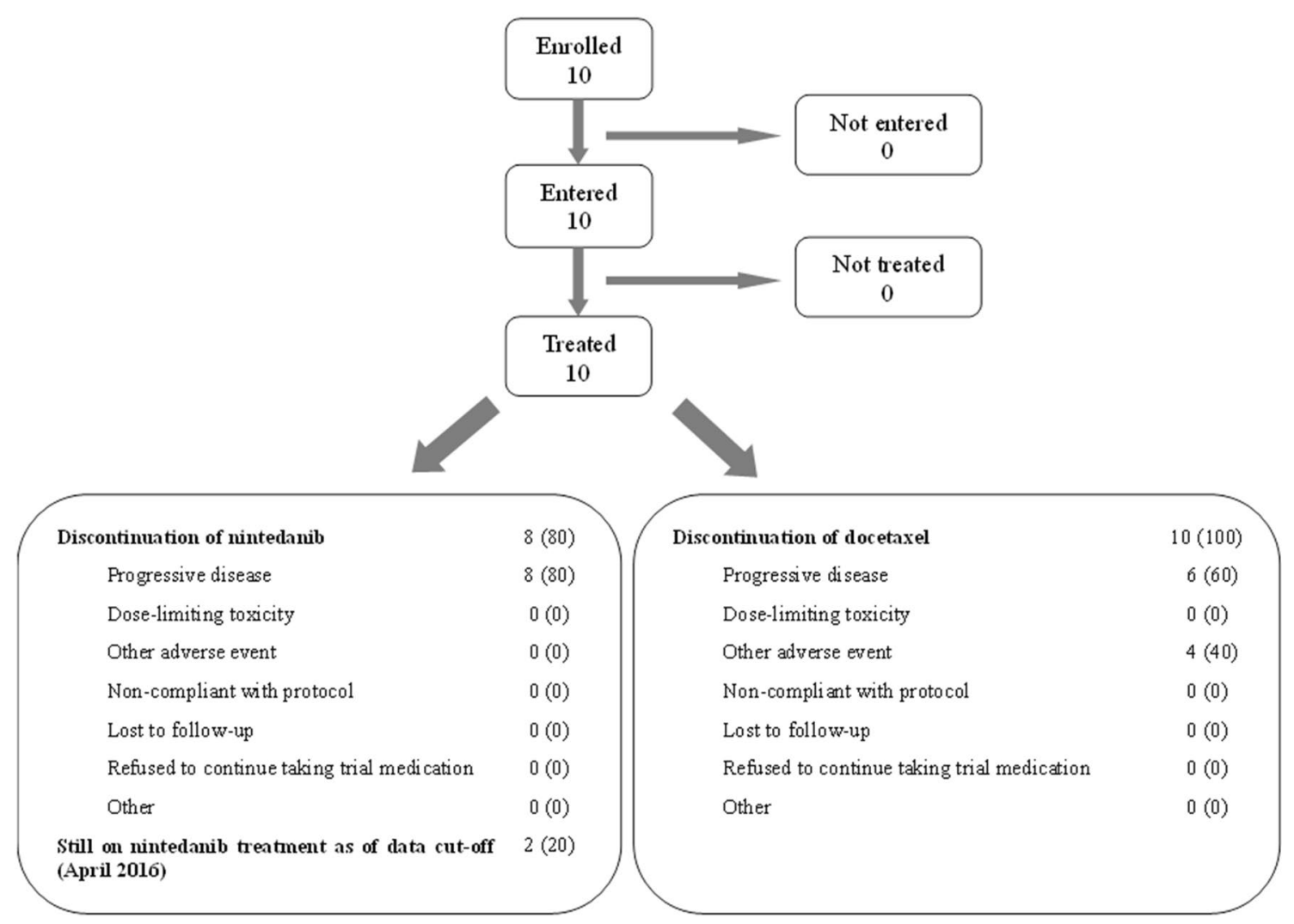

Fig. 1 Patient disposition 
Table 2 Patient demographics and baseline disease characteristics

\begin{tabular}{|c|c|}
\hline & $\begin{array}{l}\text { Nintedanib } 200 \mathrm{mg} \\
\text { with docetaxel } 75 \mathrm{mg} / \\
\mathrm{m}^{2}\end{array}$ \\
\hline Number of patients, $N(\%)$ & $10(100.0)$ \\
\hline \multicolumn{2}{|l|}{ Gender, $n(\%)$} \\
\hline Male & $2(20.0)$ \\
\hline Female & $8(80.0)$ \\
\hline \multicolumn{2}{|l|}{ Age (years) } \\
\hline Median (min-max) & $69(55-75)$ \\
\hline \multicolumn{2}{|l|}{$\operatorname{BSA}\left(\mathrm{m}^{2}\right)$} \\
\hline Median (min-max) & $1.45(1.41-1.48)$ \\
\hline \multicolumn{2}{|l|}{ Body weight (kg) } \\
\hline Median (min-max) & $48.40(40.8-51.9)$ \\
\hline \multicolumn{2}{|l|}{ Height $(\mathrm{cm})$} \\
\hline Median (min-max) & $155.5(151-165)$ \\
\hline \multicolumn{2}{|l|}{ Smoking status, $n(\%)$} \\
\hline Never smoked & $8(80.0)$ \\
\hline Ex-smoker & $2(20.0)$ \\
\hline Currently smokes & $0(0.0)$ \\
\hline \multicolumn{2}{|l|}{ ECOG PS, $n(\%)$} \\
\hline 0 & $4(40.0)$ \\
\hline 1 & $6(60.0)$ \\
\hline \multicolumn{2}{|c|}{ Metastatic disease at screening, $n(\%)$} \\
\hline No & $0(0.0)$ \\
\hline Yes & $10(100.0)$ \\
\hline \multicolumn{2}{|l|}{ Number of metastatic sites } \\
\hline Median (min-max) & $1.00(1.0-3.0)$ \\
\hline \multicolumn{2}{|c|}{ Best response to first-line, platinum-based chemotherapy, $n(\%)$} \\
\hline $\mathrm{CR} / \mathrm{PR} / \mathrm{SD}$ & $7(70.0)$ \\
\hline PD & $1(10.0)$ \\
\hline Not applicable/unknown & $2(20.0)$ \\
\hline \multicolumn{2}{|l|}{ EGFR mutation status, $n(\%)$} \\
\hline Negative & $6(60.0)$ \\
\hline Positive & $4(40.0)$ \\
\hline \multicolumn{2}{|l|}{ ALK mutation status, $n(\%)$} \\
\hline Positive & $0(0.0)$ \\
\hline Negative & $7(70.0)$ \\
\hline Unknown & $3(30.0)$ \\
\hline
\end{tabular}

$A L K$ anaplastic lymphoma kinase, $B S A$ body surface area, $C R$ complete response, ECOG PS Eastern Cooperative Oncology Group performance status, $E G F R$ epidermal growth factor receptor, $P D$ progressive disease, $P R$ partial response, $S D$ stable disease

\section{Exposure to study drug}

Overall, the median duration of exposure to trial medication (nintedanib or docetaxel) was 130.0 days (range $57-428$ days). All patients (100\%) received $\geq 1$ dose of nintedanib. The median duration of exposure to nintedanib was 129 days (range 56-427 days) and the median dose intensity was $92.8 \%$ (range $49-100 \%$ ). Of the 10 patients treated, 5 had a dose reduction of nintedanib from 200 to $150 \mathrm{mg}$ bid, and 1 patient had a second dose reduction to $100 \mathrm{mg}$ bid. Time to the first dose reduction ranged from 15 to 128 days (median 46 days). All patients (100\%) received $\geq 1$ dose of docetaxel. The median number of docetaxel cycles was 5.5 (range 3-16) and the median dose intensity was $87.3 \%$ (range 78-100\%). Of the 10 treated patients, 8 patients had a dose reduction of docetaxel from 75 to $60 \mathrm{mg} / \mathrm{m}^{2}$ and 4 patients had a second dose reduction from 60 to $50 \mathrm{mg} / \mathrm{m}^{2}$. Time to the first dose reduction ranged from 28 to 204 days (median 47.5 days).

\section{DLTs}

In cycle 1, DLTs were reported in 2 patients (20\%) (Table 3 ). These DLTs were CTCAE grade 3 liver enzyme [ALT (2 patients) and AST (2 patients)] elevations, and CTCAE grade 2 hyperbilirubinemia ( 1 patient). Of the 2 patients with DLTs in cycle 1 , patient 1 (who had CTCAE grade 3 increased ALT and CTCAE grade 3 increased AST in conjunction with CTCAE grade 2 hyperbilirubinemia in cycle 1) reported additional DLTs by the end of cycle 2 (CTCAE grade 3 increased ALT, CTCAE grade 3 increased AST, and CTCAE grade 2 hyperbilirubinemia); this patient required a second dose reduction of nintedanib (100 $\mathrm{mg}$ bid), as well as a dose reduction of docetaxel $\left(60 \mathrm{mg} / \mathrm{m}^{2}\right)$. Patient 1 was continuing nintedanib treatment at $100 \mathrm{mg}$ bid at the data cutoff (April 2016). Patient 2 (who had experienced CTCAE grade 3 increased ALT and CTCAE grade 3 increased AST) was able to be retreated with a reduced nintedanib dose of $150 \mathrm{mg}$ bid in combination with docetaxel $75 \mathrm{mg} / \mathrm{m}^{2}$, and completed cycle 2 without further DLTs; they then went on to receive 6 cycles of combination therapy. Therefore, 9 of 10 patients included in this study met the predefined criteria for the dose of nintedanib $200 \mathrm{mg}$ bid in combination with docetaxel $75 \mathrm{mg} / \mathrm{m}^{2}$ to be considered a tolerable starting dose. Eight patients completed cycle 1 without any DLTs, and 1 experienced DLTs but could be retreated with the combination of nintedanib $150 \mathrm{mg}$ plus docetaxel $75 \mathrm{mg} /$ $\mathrm{m}^{2}$ and completed cycle 2 without any further DLTs.

An additional 2 patients reported DLTs occurring after cycle 1 (patients 3 and 4). Patient 3 reported CTCAE grade 3 increased AST and patient 4 reported CTCAE grade 3 increased ALT. In both patients, nintedanib was successfully re-introduced at $150 \mathrm{mg}$ bid.

\section{Safety}

All patients (10 patients, 100\%) experienced $\geq 1 \mathrm{AE}$ during the on-treatment period, all of which were considered to be drug related by the investigator (Table 4). The most common AEs were decreased neutrophil count and decreased white blood cell (WBC) count (10 patients each, 100\%), alopecia 
Table 3 Observed DLTs

\begin{tabular}{|c|c|c|c|}
\hline Patient & $\begin{array}{l}\text { Nintedanib dose at onset of } \\
\mathrm{AE}(\mathrm{mg})\end{array}$ & Grade and preferred term & Cycle \\
\hline \multicolumn{4}{|c|}{ Patients who experienced DLTs in cycle 1 (with or without DLTs after cycle 1) } \\
\hline \multirow[t]{2}{*}{1} & 200 bid & $\begin{array}{c}\text { Grade } 3 \text { increase in ALT, grade } 3 \text { increase } \\
\text { in AST and grade } 2 \text { hyperbilirubinemia }\end{array}$ & Cycle 1 \\
\hline & 150 bid & $\begin{array}{c}\text { Grade } 3 \text { increase in ALT, grade } 3 \text { increase } \\
\text { in AST and grade } 2 \text { hyperbilirubinemia }\end{array}$ & After cycle 1 \\
\hline 2 & 200 bid & Grade 3 increase in ALT and AST & Cycle 1 \\
\hline \multicolumn{4}{|c|}{ Patients who experienced DLTs only after cycle 1} \\
\hline 3 & 200 bid & Grade 3 increase in AST & After cycle 1 \\
\hline 4 & 200 bid & Grade 3 increase in ALT & After cycle 1 \\
\hline
\end{tabular}

$A E$ adverse event, $A L T$ alanine aminotransferase, $A S T$ aspartate aminotransferase, bid twice daily, $D L T$ dose-limiting toxicity

(9 patients, 90\%), increased ALT (8 patients, $80 \%$ ), increased AST (7 patients, 70\%), constipation, diarrhea, and nausea (5 patients each, $50 \%$ ) (Table 4). The most common grade $\geq 3$ AEs were decreased neutrophil count, decreased WBC count (10 patients each, 100\%), increased ALT, increased AST (3 patients each, 30\%), increased GGT, decreased lymphocyte count, and febrile neutropenia (2 patients each, 20\%) (Table 4). Both cases of febrile neutropenia were grade 3.

The highest CTCAE grades reported were grade 4 for 9 patients $(90 \%)$ and grade 3 for 1 patient (10\%). No fatal (grade 5) AEs were reported. No patients experienced AEs that led to discontinuation of nintedanib, whereas 4 patients experienced AEs leading to discontinuation of docetaxel.

AEs leading to dose reduction of nintedanib and docetaxel were reported for $5(50 \%)$ patients and $8(80 \%)$ patients, respectively. The most common AEs leading to dose reduction of nintedanib were increased ALT and increased AST ( $30 \%$ each); the most common AE leading to dose reduction of docetaxel was decreased neutrophil count (40\%), followed by decreased WBC count and febrile neutropenia ( $20 \%$ each). A total of 5 SAEs were reported in 5 patients during treatment. None of the SAEs were considered to be drug related by the investigator and none led to dose reduction or discontinuation of study medication.

Overall, liver enzyme elevations of $>1$ CTCAE grade from baseline were observed in $5(50 \%)$ patients for AST, 6 (60\%) patients for ALT, 7 (70\%) patients for GGT, 1 (10\%) patient for alkaline phosphatase, and $1(10 \%)$ patient for total bilirubin. Combined liver transaminase and bilirubin elevations were reported for $1(10 \%)$ of 10 treated patients; this patient (patient 1) was a potential Hy's law case (alkaline phosphatase levels were consistently below 2 times the upper limit of normal and there was no alternative explanation for liver enzyme elevation). CTCAE grade 3 or 4 decreases in WBC count and neutrophil count were observed in all patients. Clinically significant values of laboratory tests were mainly attributed to hematologic and liver parameter-related side effects of the therapy; other significant values included low albumin $(30 \%)$, high glucose $(20 \%)$, high calcium, low phosphate, and high lactate dehydrogenase ( $10 \%$ each). No clinically significant values were observed for coagulation parameters.

\section{PK}

After single oral administration of $200 \mathrm{mg}$ nintedanib, the plasma concentration of nintedanib and its metabolite, BIBF $1202 \mathrm{ZW}$, reached its maximum, with median time of $C_{\max }$ $\left(t_{\max }\right)$ values of 2.00 and $3.98 \mathrm{~h}$, and then declined with a geometric mean half-life of 6.97 and $5.88 \mathrm{~h}$, respectively. After single oral administration of $200 \mathrm{mg}$ nintedanib, the plasma concentration of BIBF 1202 glucuronide reached its maximum, with a median $t_{\max }$ value of $9.97 \mathrm{~h}$, and then declined slightly and remained at almost the same level up to $24 \mathrm{~h}$ after nintedanib administration.

Geometric mean values of the ratio of exposures (AUC $_{0-12}$ and $C_{\max }$ ) of BIBF $1202 \mathrm{ZW}$ relative to exposures of nintedanib were 1.05 and 0.847 , respectively. Geometric mean values of the ratio of exposures for the second metabolite BIBF 1202 glucuronide relative to the exposures of nintedanib were 1.25 and 0.725 , respectively. The geometric mean values of plasma exposure, measured by AUC $0-\mathrm{tz}$, in cycle 1 were higher in patients with DLTs $(n=2)$ versus those without $(n=7)$. This trend could be observed for the free-base form of nintedanib (614 vs. $289 \mathrm{ng} \times \mathrm{h} /$ $\mathrm{mL}$, respectively), BIBF $1202 \mathrm{ZW}$ (696 vs. $301 \mathrm{ng} \times \mathrm{h} /$ $\mathrm{mL}$, respectively), and BIBF 1202 glucuronide (1960 vs. $865 \mathrm{ng} \times \mathrm{h} / \mathrm{mL}$, respectively). However, owing to the low number of patients, no firm conclusions about this observation can be reached.

After intravenous administration, the plasma concentration of docetaxel reached maximum at around the end of infusion and then declined, with a half-life of $20.7 \mathrm{~h}$. Geometric mean values of AUCs in cycle 2 were comparable to those in cycle 1 . 
Table 4 AEs that were reported for more than 1 patient
System organ class/preferred term

Nintedanib $200 \mathrm{mg}$ with docetaxel $75 \mathrm{mg} / \mathrm{m}^{2}$

\begin{tabular}{|c|c|c|}
\hline & \\
\hline & $\begin{array}{l}\text { All grades } \\
N(\%)\end{array}$ & $\begin{array}{l}\text { Grade } 3 / 4 \\
N(\%)\end{array}$ \\
\hline Number of patients & $10(100.0)$ & $10(100.0)$ \\
\hline Total with any AEs & $10(100.0)$ & $10(100.0)$ \\
\hline Blood and lymphatic system disorders & $2(20.0)$ & $2(20.0)$ \\
\hline Febrile neutropenia & $2(20.0)$ & $2(20.0)$ \\
\hline Eye disorders & $5(50.0)$ & $0(0.0)$ \\
\hline Lacrimation increased & $2(20.0)$ & $0(0.0)$ \\
\hline Gastrointestinal disorders & $9(90.0)$ & $0(0.0)$ \\
\hline Constipation & $5(50.0)$ & $0(0.0)$ \\
\hline Diarrhea & $5(50.0)$ & $0(0.0)$ \\
\hline Nausea & $5(50.0)$ & $0(0.0)$ \\
\hline Vomiting & $2(20.0)$ & $0(0.0)$ \\
\hline General disorders and administration-site conditions & $8(80.0)$ & $0(0.0)$ \\
\hline Fatigue & $4(40.0)$ & $0(0.0)$ \\
\hline Edema peripheral & $3(30.0)$ & $0(0.0)$ \\
\hline Pyrexia & $3(30.0)$ & $0(0.0)$ \\
\hline Malaise & $2(20.0)$ & $0(0.0)$ \\
\hline Infections and infestations & $6(60.0)$ & $0(0.0)$ \\
\hline Cystitis & $2(20.0)$ & $0(0.0)$ \\
\hline Upper respiratory tract infection & $2(20.0)$ & $0(0.0)$ \\
\hline Investigations & $10(100.0)$ & $10(100.0)$ \\
\hline Neutrophil count decreased & $10(100.0)$ & $10(100.0)$ \\
\hline WBC count decreased & $10(100.0)$ & $10(100.0)$ \\
\hline ALT increased & $8(80.0)$ & $3(30.0)$ \\
\hline AST increased & $7(70.0)$ & $3(30.0)$ \\
\hline GGT increased & $4(40.0)$ & $2(20.0)$ \\
\hline Blood alkaline phosphatase increased & $2(20.0)$ & $0(0.0)$ \\
\hline Hemoglobin decreased & $2(20.0)$ & $0(0.0)$ \\
\hline Lymphocyte count decreased & $2(20.0)$ & $2(20.0)$ \\
\hline Metabolism and nutrition disorders & $4(40.0)$ & $1(10.0)$ \\
\hline Decreased appetite & $4(40.0)$ & $0(0.0)$ \\
\hline Musculoskeletal and connective tissue disorders & $2(20.0)$ & $0(0.0)$ \\
\hline Myalgia & $2(20.0)$ & $0(0.0)$ \\
\hline Nervous system disorders & $5(50.0)$ & $0(0.0)$ \\
\hline Peripheral sensory neuropathy & $4(40.0)$ & $0(0.0)$ \\
\hline Dysgeusia & $3(30.0)$ & $0(0.0)$ \\
\hline Headache & $2(20.0)$ & $0(0.0)$ \\
\hline Psychiatric disorders & $3(30.0)$ & $0(0.0)$ \\
\hline Insomnia & $3(30.0)$ & $0(0.0)$ \\
\hline Skin and subcutaneous tissue disorders & $9(90.0)$ & $0(0.0)$ \\
\hline Alopecia & $9(90.0)$ & $0(0.0)$ \\
\hline Palmar-Plantar erythrodysesthesia syndrome & $2(20.0)$ & $0(0.0)$ \\
\hline Pruritus & $2(20.0)$ & $0(0.0)$ \\
\hline Rash & $2(20.0)$ & $0(0.0)$ \\
\hline Vascular disorders & $4(40.0)$ & $1(10.0)$ \\
\hline Flushing & $2(20.0)$ & $0(0.0)$ \\
\hline
\end{tabular}

$A E$ adverse event, $A L T$ alanine aminotransferase, $A S T$ aspartate aminotransferase, GGT gamma-glutamyltransferase, $W B C$ white blood cell 


\section{Tumor response}

Seven patients were evaluable for tumor response in the treated set $(n=10)$. In this patient set, the best response was a partial response in 4 patients $(40 \%)$ and stable disease in 3 patients (30\%). The objective response rate was $40 \%$ and the disease control rate was $70 \%$. All patients with target lesions at baseline (7 patients) achieved disease control.

\section{Discussion}

This open-label feasibility trial was conducted to determine the tolerability of nintedanib $200 \mathrm{mg}$ bid in combination with docetaxel $75 \mathrm{mg} / \mathrm{m}^{2}$ as a starting dose in Japanese patients with a $\mathrm{BSA}<1.5 \mathrm{~m}^{2}$ and locally advanced or metastatic lung after the failure of platinum-based chemotherapy.

This investigation into an appropriate starting dose was initiated given the clinical benefits of nintedanib combination therapy previously observed in patients with lung adenocarcinoma in the global phase III LUME-Lung 1 trial [10].

Using a similar definition of DLTs as per a previous phase I, open-label trial [13], DLTs were reported for $2(20 \%)$ of 10 patients in cycle 1 . DLTs were CTCAE grade 3 liver enzyme elevations (ALT and AST), in conjunction with CTCAE grade 2 hyperbilirubinemia in 1 patient. One of the 2 patients was able to be retreated with a reduced nintedanib dose of $150 \mathrm{mg}$ bid in combination with docetaxel $75 \mathrm{mg} /$ $\mathrm{m}^{2}$ and completed cycle 2 without any further DLT. The second patient, who had CTCAE grade 2 hyperbilirubinemia, required a second dose reduction of nintedanib (100 mg bid). In patients who reported DLTs, elevated indices of exposure of the free-base form of nintedanib and its metabolites relative to patients without DLTs were observed; however, it should be noted that the patient numbers were low and this trend would be expected given that increased drug exposure is associated with an increased severity of AEs [14].

Differences were observed in the proportion of DLTs reported in cycle 1 of our study (40\%) and a previous phase I, open-label trial (100\%), which had comparable numbers of patients with BSA $<1.5 \mathrm{~m}^{2}$; these minor differences can be attributable to the small sample size of patients in both studies.

Overall, the safety profile of the combination therapy was consistent with previous clinical trials with nintedanib and the known safety profile of docetaxel, with the most common drug-related AEs being myelotoxicity (neutropenia and leukopenia), liver enzyme elevations (increased AST and ALT), gastrointestinal AEs (diarrhea and nausea), and alopecia. Neutropenia and leukopenia were CTCAE grade 3 or 4 in all patients; however, these events were manageable with adequate supportive treatment or dose reduction of docetaxel, and no events lasted over 7 days to qualify as a DLT. A total of 4 patients had liver enzyme elevations of CTCAE grade 3. These events were accompanied by a moderate decrease in parameters associated with liver function (pre-albumin, albumin, and cholinesterase) or abnormality in abdominal imaging; however, all tended to be resolved after treatment interruption and were manageable. Treatment with nintedanib was successfully re-introduced at lower doses in all patients. Clinical laboratory safety parameter findings in this trial were consistent with the pattern of the observed AEs and were mainly attributed to liver parameter elevations associated with nintedanib and hematological side effects of docetaxel.

Although the starting dose of nintedanib $200 \mathrm{mg}$ bid in combination with docetaxel $75 \mathrm{mg} / \mathrm{m}^{2}$ was considered to be well-tolerated in Japanese patients with a BSA $<1.5 \mathrm{~m}^{2}$, it should be noted that the frequency of patients who required $\geq 1$ dose reduction of trial medications was high in this trial (nintedanib 50\%, docetaxel 80\%) compared to the adenocarcinoma subpopulation in the phase III LUME-Lung 1 trial (nintedanib 21.9\%, docetaxel 16.9\%) [10]. In our trial, geometric mean values of AUC for docetaxel were comparable in cycles 1 and 2, suggesting that there is no effect of nintedanib on docetaxel exposure in the applied treatment schedule in patients with a $\mathrm{BSA}<1.5 \mathrm{~m}^{2}$. This is in agreement with previous clinical data in non-Japanese and Japanese patients [13, 15].

Overall, $4(40 \%)$ of 10 patients achieved a partial response and all patients with target lesions achieved disease control. Taking into consideration the small sample size, these findings indicate a clinical benefit of nintedanib plus docetaxel in Japanese patients with lung adenocarcinoma after platinum-based chemotherapy, and are consistent with results from the phase III LUME-Lung 1 trial [10].

\section{Conclusion}

Results from this open-label feasibility study demonstrated that nintedanib $200 \mathrm{mg}$ bid in combination with docetaxel $75 \mathrm{mg} / \mathrm{m}^{2}$ in a 21-day cycle is a tolerable starting dose in Japanese patients with a BSA $<1.5 \mathrm{~m}^{2}$ and locally advanced or metastatic lung adenocarcinoma. In addition, preliminary efficacy analyses indicate that this dose exhibited antitumor activity.

Acknowledgements Medical writing assistance, supported financially by Boehringer Ingelheim, was provided by Syneos Health Communications during the preparation of this manuscript.

Funding This work was supported by Boehringer Ingelheim. 


\section{Compliance with ethical standards}

Conflict of interest Hidehito Horinouchi has received both grants and personal fees from Boehringer Ingelheim, Chugai, Taiho and Novartis; grants from Merck Sharp \& Dohme (MSD), Merck Serono, Astellas, Genomic Health and Bristol-Myers Squibb; and personal fees from Eli Lilly, Kyowa-Kirin and AstraZeneca. Koji Takeda has received both grants and personal fees from AstraZeneca, Boehringer Ingelheim, Bristol-Myers Squibb, Chugai, Eli Lilly, Ono, Taiho and Pfizer; grants from Merck Serono, Astellas, AbbVie and MSD; and personal fees from Daiichi Sankyo, Kyowa Hakko Kirin Co. Ltd, and Novartis. Masayuki Takeda has nothing to disclose. Noboru Yamamoto has received research grants from Chugai, Taiho, Eisai, Eli Lilly, Quintiles, Astellas, Bristol-Myers Squibb, Novartis, Daiichi Sankyo, Pfizer, Boehringer Ingelheim, Kyowa-Hakko Kirin, Bayer, Ono and Takeda, and honoraria from Ono, Chugai, AstraZeneca, Pfizer, Eli Lilly and Bristol-Myers Squibb. Koichi Goto has received both grants and personal fees from Boehringer Ingelheim, AstraZeneca, AbbVie Stemcentrx, Bristol-Myers Squibb, Chugai, Daiichi Sankyo, Eli Lilly, Kyowa Hakko Kirin, MSD, Novartis Pharma, Ono, Pfizer, Riken Genesis, Taiho and Merck Serono; grants from Astellas, Amgen Astellas BioPharma, Eisai, Ignyta, Oxonc, Takeda Pharmaceutical and Sumitomo Dainippon Pharma; and personal fees from Abbott Japan, F. Hoffmann-La Roche, GlaxoSmithKline, Life Technologies Japan, Nippon Kayaku, Otsuka Pharmaceutical, Quintiles and SRL. Hirotsuga Kenmotsu has received grants, personal fees, honoraria and research funds from Boehringer Ingelheim, AstraZeneca and Chugai, and received both personal fees and honoraria from Ono, Bristol-Myers Squibb, Eli Lilly, Kyowa Hakko Kirin and Novartis Pharma. Terufumi Kato has requested grants and personal fees from Boehringer Ingelheim, AbbVie, AstraZeneca, Bristol-Myers Squibb, Chugai, Eli Lilly, Kyowa Kirin, MSD, Ono, Pfizer, Quintiles, Taiho and Merck Sereno; grants from Astellas Parexel; and received personal fees from Novartis, F. Hoffmann-La Roche and Sumitomo Dainippon. Kazuhiko Nakagawa has received both grants and personal fees from Daiichi Sankyo, Astellas Pharma, AstraZeneca, EPS Holdings, Ono, Kyowa Hakko Kirin, Chugai, Nippon Boehringer Ingelheim, Eli Lilly, Pfizer, Bristol-Myers Squibb, Novartis and Taiho; grants from Quintiles, Japan Clinical Research Operations, Eisai, PPD-SNBL K.K., Takeda, AbbVie, Yakult Honsha, Parexel, Otsuka, AC Medical and Merck Serono; and personal fees from Showa Yakuhin Kako, SymBio Pharmaceuticals, MSD K.K. and Ayumi Pharmaceutical Corporation. Nassim Morsli was an employee of Boehringer Ingelheim and is now an employee of AstraZeneca. Isao Saito, Akiko Sarashina and Tetsuya Tanaka are all employees of Boehringer Ingelheim.

Ethical approval All procedures performed in studies involving human participants were in accordance with the ethical standards of the institutional and/or national research committee and with the 1964 Helsinki declaration and its later amendments or comparable ethical standards.

Open Access This article is distributed under the terms of the Creative Commons Attribution 4.0 International License (http://creativeco mmons.org/licenses/by/4.0/), which permits unrestricted use, distribution, and reproduction in any medium, provided you give appropriate credit to the original author(s) and the source, provide a link to the Creative Commons license, and indicate if changes were made.

\section{References}

1. National Comprehensive Cancer Network ${ }^{\circledR}$. NCCN Clinical Practice Guidelines in Oncology (NCCN Guidelines ${ }^{\circledR}$ ): Non-Small Cell Lung Cancer, version 5. http://www.nccn.org. Accessed 15 Aug 2017

2. Novello S, Barlesi F, Califano R et al (2016) Metastatic non-smallcell lung cancer: ESMO Clinical Practice Guidelines for diagnosis, treatment and follow-up. Ann Oncol 27:v1-v27

3. US Food \& Drug Administration. Opdivo (nivolumab) prescribing information. https://www.accessdata.fda.gov/drugsatfda_docs/ label/2016/125554s019lbl.pdf. Accessed 20 Oct 2017

4. US Food \& Drug Administration. Keytruda (pembrolizumab) prescribing information. https://www.accessdata.fda.gov/drugs atfda_docs/label/2016/125514s012lbl.pdf. Accessed 20 Oct 2017

5. US Food \& Drug Administration. Tecentriq (atezolizumab) prescribing information. https://www.accessdata.fda.gov/drugsatfda _docs/label/2016/761034s0001bl.pdf. Accessed 20 Oct 2017

6. Garon EB, Herbst RS, Kim D-W et al (2016) Pembrolizumab vs docetaxel for previously treated advanced NSCLC with a PD-L1 tumor proportion score (TPS) $1 \%-49 \%$ : results from KEYNOTE-010. J Clin Oncol 34(Suppl.):9024

7. Hilberg F, Roth GJ, Krssak M et al (2008) BIBF 1120: triple angiokinase inhibitor with sustained receptor blockade and good antitumor efficacy. Cancer Res 68:4774-4782

8. NICE Guidance. Nintedanib for previously treated locally advanced, metastatic, or locally recurrent non-small cell lung cancer. https://www.nice.org.uk/guidance/TA347. Accessed 20 Oct 2017

9. European Medicines Agency. Vargatef summary of product characteristics. http://www.ema.europa.eu/docs/en_GB/document_ library/EPAR_-_Product_Information/human/002569/WC500 179970.pdf. Accessed 20 Oct 2017

10. Reck M, Kaiser R, Mellemgaard A et al (2014) Docetaxel plus nintedanib versus docetaxel plus placebo in patients with previously treated non-small-cell lung cancer (LUME-Lung 1): a phase 3, double-blind, randomised controlled trial. Lancet Oncol 2014 $15: 143-155$

11. Mross K, Stefanic M, Gmehling D et al (2010) Phase I study of the angiogenesis inhibitor BIBF 1120 in patients with advanced solid tumors. Clin Cancer Res 16:311-319

12. Okamoto I, Kaneda H, Satoh T et al (2010) Phase I safety, pharmacokinetic, and biomarker study of BIBF 1120, an oral triple tyrosine kinase inhibitor in patients with advanced solid tumors. Mol Cancer Ther 9:2825-2833

13. Okamoto I, Miyazaki M, Takeda M et al (2015) Tolerability of nintedanib (BIBF 1120) in combination with docetaxel: a phase 1 study in Japanese patients with previously treated non-small-cell lung cancer. J Thorac Oncol 10:346-352

14. Iasonos A, Gounder M, Spriggs DR et al (2012) The impact of non-drug-related toxicities on the estimation of the maximum tolerated dose in phase I trials. Clin Cancer Res 18:5179-5187

15. Bousquet G, Alexandre J, Le Tourneau C et al (2011) Phase I study of BIBF 1120 with docetaxel and prednisone in metastatic chemo-naive hormone-refractory prostate cancer patients. Br J Cancer 105:1640-1645 


\section{Affiliations}

\section{Noboru Yamamoto ${ }^{1} \cdot$ Hirotsugu Kenmotsu $^{2} \cdot$ Koichi Goto $^{3} \cdot$ Koji Takeda $^{4} \cdot$ Terufumi Kato $^{5} \cdot$ Masayuki Takeda $^{6}$. Hidehito Horinouchi ${ }^{1} \cdot$ Isao Saito $^{7} \cdot$ Akiko Sarashina $^{8} \cdot$ Tetsuya Tanaka $^{9} \cdot$ Nassim Morsli $^{10} \cdot$ Kazuhiko Nakagawa $^{6}$}

Hirotsugu Kenmotsu

h.kenmotsu@scchr.jp

Koichi Goto

kgoto@east.ncc.go.jp

Koji Takeda

kkk-take@ga2.so-net.ne.jp

Terufumi Kato

terufumikato@gmail.com

Masayuki Takeda

takedamasa2004@yahoo.co.jp

Hidehito Horinouchi

hhorinou@ncc.go.jp

Isao Saito

isao.saito@boehringer-ingelheim.com

Akiko Sarashina

akiko.sarashina@boehringer-ingelheim.com

Tetsuya Tanaka

tetsuya.tanaka.ext@boehringer-ingelheim.com

Nassim Morsli

nassim.morsli@astrazeneca.com
Kazuhiko Nakagawa

nakagawa@med.kindai.ac.jp

1 Department of Thoracic Oncology, National Cancer Center Hospital, Tokyo, Japan

2 Division of Thoracic Oncology, Shizuoka Cancer Center, Shizuoka, Japan

3 Department of Thoracic Oncology, National Cancer Center Hospital East, Kashiwa, Japan

4 Department of Medical Oncology, Osaka City General Hospital, Osaka, Japan

5 Department of Respiratory Medicine, Kanagawa Cardiovascular and Respiratory Center, Yokohama, Japan

6 Department of Medical Oncology, Kindai University Faculty of Medicine, Osaka, Japan

7 Nippon Boehringer Ingelheim, Tokyo, Japan

8 Nippon Boehringer Ingelheim, Kobe, Hyogo, Japan

9 EPS Corporation, Tokyo, Japan

10 AstraZeneca Pharmaceuticals LP, Cambridge, UK 